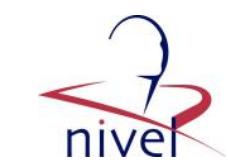

\begin{tabular}{|l|l|}
$\begin{array}{l}\text { Postprint } \\
\text { Version }\end{array}$ & 1.0 \\
\hline Journal website & https://link.springer.com/article/10.1007\%2Fs12414-017-0245-7 \\
\cline { 2 - 2 } Pubmed link & \\
\hline DOI & $10.1007 / s 12414-017-0245-7$ \\
\hline
\end{tabular}

This is a NIVEL certified Post Print, more info at http://www.nivel.eu

\title{
Multimorbiditeit en polyfarmacie
}

FRANÇOIS G. SCHELLEVIS ${ }^{1}$

${ }^{1}$.senior researcher, NIVEL, Utrecht, hoogleraar huisartsgeneeskunde, afdeling Huisartsgeneeskunde en Ouderengeneeskunde, Amsterdam Public Health Research Institute, VUmc, Amsterdam.

De veroudering van de bevolking zal in de huisartsenpraktijk een toename van het aantal patiënten met complexe hulpvragen en problemen tot gevolg hebben. Huisartsen zullen daarop moeten anticiperen door het aanpassen van hun praktijkvoering en het huisartsgeneeskundig handelen. Deze bijdrage biedt huisartsen praktische handvatten voor het omgaan met patiënten met multimorbiditeit (het bestaan van meerdere chronische ziekten bij eenzelfde persoon) en polyfarmacie (het gelijktijdig gebruik van vijf of meer verschillende geneesmiddelen). De Ariadne principles beschrijven een systematische werkwijze in de spreekkamer bij patiënten met multimorbiditeit die een nieuw gezondheidsprobleem aan de huisarts de presenteren. In deze werkwijze wordt bestaande wetenschappelijke kennis over de behandeling van afzonderlijke ziekten meegewogen in een gepersonaliseerd behandelplan, waarin ook rekening gehouden wordt met de voorkeuren en prioriteiten van de patiënt. Multimorbiditeit hangt samen met polyfarmacie, maar leidt ook tot interacties tussen ziekten en geneesmiddelen. Dit maakt de medicamenteuze behandeling van patiënten met multimorbiditeit complex. Voor polyfarmaciepatiënten wordt een periodieke medicatiereview aanbevolen om het geneesmiddelengebruik te optimaliseren; de multidisciplinaire richtlijn Polyfarmacie bij ouderen bevat veel praktische aanbevelingen hiervoor. Onduidelijk is nog welke doelgroep het meest baat heeft bij een periodieke medicatiebeoordeling. Voor het welslagen van de medicatiereview en het herzien van het medicatiebeleid is betrokkenheid van de patiënt onontbeerlijk.

\section{INLEIDING}

We worden met z'n allen gemiddeld ouder, en ouderen zullen een steeds groter deel van de bevolking gaan uitmaken. In 1910 was de levensverwachting bij de geboorte 58 jaar voor mannen en 65 jaar voor vrouwen; deze is in ruim een eeuw toegenomen tot 80 jaar voor mannen en tot 83 jaar voor vrouwen [1], een ongekende stijging. Vanwege het sterke verband tussen leeftijd en de incidentie en prevalentie van chronische ziekten zullen er in de toekomst ook meer mensen zijn met een of meer chronische ziekten.

Voor huisartsen betekenen deze ontwikkelingen een geleidelijke, maar gestage stijging van de gemiddelde leeftijd van de spreekuurbezoekers en van het aantal patiënten dat thuis bezocht moet worden. Ook de aard van de vragen en problemen waarmee huisartsen te maken krijgen verandert: meer patiënten dan voorheen hebben 
een of meer chronische ziekten, meer patiënten hebben een vroeger fatale ziekte (acuut myocardinfarct, kanker) overleefd, meer patiënten gebruiken veel verschillende geneesmiddelen, en bij meer patiënten zijn meerdere zorgverleners betrokken. Van huisartsen wordt flexibiliteit verwacht in het omgaan met deze veranderingen in de vraag naar zorg. Huisartsen zullen daarop moeten anticiperen door het aanpassen van hun praktijkvoering en hun huisartsgeneeskundig handelen, uiteraard rekening houdend met bestaande evidence.

Deze bijdrage gaat in op enkele van de hiervoor genoemde ontwikkelingen, met name op multimorbiditeit (het bestaan van meerdere chronische ziekten) en polyfarmacie (het gebruik van meerdere verschillende geneesmiddelen). Doel is de lezer praktische handvatten te bieden voor het omgaan met patiënten met multimorbiditeit in het algemeen en in het bijzonder met polyfarmacie in de dagelijkse praktijk.

\section{BEGRIPPEN}

De term 'multimorbiditeit' verwijst naar het bestaan van meer dan één ziekte bij een persoon [2]. Meestal beperkt de definitie zich tot chronische ziekten. Een verwante term, die regelmatig gebruikt wordt, is 'comorbiditeit'; men spreekt dan over 'bijkomende' ziekten bij een indexziekte, bijvoorbeeld COPD of gonartrose bij diabetes mellitus [3]. In het kader van de zorg voor ouderen komen ook de termen frailty (kwetsbaarheid) en disability (functiebeperking) vaak voor. De term multimorbiditeit verwijst naar het bestaan van multipele ziekten, frailty in somatische zin naar de labiliteit of kwetsbaarheid van het functioneren van verschillende orgaansystemen of breder, van het biopsychosociaal functioneren, disability verwijst naar beperkingen in het functioneren in de activiteiten van het dagelijks leven. Hoewel deze begrippen verwant zijn en op eenzelfde persoon van toepassing kunnen zijn [4], verwijzen ze naar verschillende aspecten van de gezondheid van ouderen. De meest gebruikte definitie van 'polyfarmacie' is het chronisch gebruik van vijf of meer geneesmiddelen uit verschillende farmacotherapeutische groepen (bijvoorbeeld antihypertensiva, antidiabetica, analgetica, anxiolytica; [5]).

\section{MULTIMORBIDITEIT IN DE SPREEKKAMER}

Patiënten met multimorbiditeit appelleren aan het generalistische karakter van de huisartsgeneeskunde. Huisartsen zijn de meest aangewezen zorgverleners, omdat zij het meest complete overzicht hebben over de verschillende ziekten en gezondheidsproblemen, kunnen adviseren over de behandeling (zowel medicamenteus als niet-medicamenteus), in overleg met de patiënt (en eventuele mantelzorger) prioriteiten kunnen stellen en zo nodig andere zorgverleners daarbij kunnen betrekken. De uitdaging voor huisartsen is hierbij ook zoveel mogelijk gebruik te maken van bestaande wetenschappelijke kennis over de behandeling van de afzonderlijke ziekten, terwijl de kennis over de behandeling in geval van combinaties van ziekten schaars is.

Een aantal internationale experts heeft hiervoor een systematische aanpak voorgesteld [6]. Deze Ariadne principles beschrijven een systematische werkwijze bij patiënten met multimorbiditeit die een nieuw gezondheidsprobleem aan de huisarts presenteren (fig. 1).

Als eerste stap beoordeelt de huisarts in hoeverre er sprake is van samenhang met reeds bestaande ziekten of problemen of de behandeling daarvan (interaction 
assessment), en vindt verdere diagnostiek plaats. Het voorstel voor een eventuele behandeling wordt met de patiënt besproken, waarbij de huisarts de voorkeuren van de patiënt en prioriteiten laat meewegen. Dit leidt dan tot een gepersonaliseerd behandelplan met realistische doelen, rekening houdend met de interacties tussen ziekten en behandelingen. In deze systematische aanpak brengt de huisarts kennis in over de behandeling van de bestaande ziekten, en weegt deze af tegen mogelijke interacties en tegen de persoonlijke voorkeuren en prioriteiten van de patiënt. Daarmee is de bestaande kennis over de behandeling van afzonderlijke ziekten (zoals vastgelegd in bijvoorbeeld NHG-Standaarden) niet onbruikbaar bij patiënten met multimorbiditeit, maar wordt deze in de persoonlijke context van de patiënt meegewogen [7].

\section{[FIGUUR 1]}

\section{Polyfarmacie}

Uiteraard zijn multimorbiditeit en polyfarmacie aan elkaar gerelateerd: hoe meer ziekten een patiënt heeft, hoe meer geneesmiddelen een patiënt gebruikt [8]. Er worden drie vormen van interacties onderscheiden: disease-disease, diseasedrug/drug-disease en drug-drug [9]. Deze interacties wijzen op onderlinge beïnvloeding van

- de ene ziekte op de andere (bijvoorbeeld: bemoeilijkte diagnostiek van hartfalen bij patiënten met COPD);

- een ziekte op het gebruik of de werkzaamheid van een geneesmiddel (bijvoorbeeld: verminderde therapietrouw bij depressieve patiënten) of andersom (bijvoorbeeld: gebruik van benzodiazepines verhoogt de kans op vallen en fracturen bij osteoporose);

- de werkzaamheid van geneesmiddelen (bijvoorbeeld: gelijktijdig gebruik van een NSAID en digoxine bij verminderde nierfunctie kan tot een stijging van de plasmaspiegels van beide middelen leiden met ernstige bijwerkingen als gevolg).

Deze interacties tussen ziekten en geneesmiddelen maken de behandeling van patiënten met multimorbiditeit complex, ook omdat de bestaande richtlijnen voor de behandeling van de afzonderlijke ziekten geen concrete handvatten bieden voor de behandeling van combinaties van ziekten. Dit is complexe huisartsgeneeskunde, en het blijkt ook dat huisartsen dit moeilijk vinden. Dit wordt bijvoorbeeld zichtbaar in de grote variatie in het aantal polyfarmaciepatiënten per praktijk: een factor 2,6 verschil tussen de praktijk met het laagste en het hoogste percentage ([10] en fig. 2). Recent kwalitatief onderzoek liet ook zien dat huisartsen verschillende strategieën volgen om het medicatieregime bij patiënten met complexe problemen aan te passen , en behoefte hebben aan meer ondersteuning daarbij [11]. De multidisciplinaire richtlijn Polyfarmacie bij ouderen biedt daarvoor wel enig houvast.

\section{[FIGUUR 2]}

\section{MULTIDISCIPLINAIRE RICHTLIJN 'POLYFARMACIE BIJ OUDEREN'}

In 2012 is de multidisciplinaire richtlijn Polyfarmacie bij ouderen tot stand gekomen [5]. Deze richtlijn geeft achtergrondinformatie over het geneesmiddelengebruik bij 
ouderen, een overzicht van veelvoorkomende interacties en bijwerkingen, en indicaties voor het voorschrijven van een geneesmiddel of stoppen van medicatie (zgn. START- en STOP-criteria). Daarmee bevat deze richtlijn veel praktische aanbevelingen voor het optimaliseren van het geneesmiddelengebruik bij ouderen. Naast deze specifieke aanbevelingen adviseren de richtlijnmakers om ten minste eenmaal per jaar een systematische medicatiebeoordeling (clinical medication review) uit te voeren bij patiënten van 65 jaar en ouder die vijf of meer geneesmiddelen gebruiken en die voldoen aan ten minste een van de volgende kenmerken:

- verminderde nierfunctie (eGFR $<50 \mathrm{ml} / \mathrm{min} / 1,73 \mathrm{~m}^{2}$ );

- verminderde cognitie (dementie of aanwijzingen voor geheugenstoornissen of andere cognitieve stoornissen);

- verhoogd valrisico (een of meer keren gevallen in de afgelopen twaalf maanden);

- signalen van verminderde therapietrouw;

- niet zelfstandig wonend (verzorgings- of verpleeghuis);

- niet-geplande ziekenhuisopname.

Een medicatiebeoordeling bestaat uit verschillende stappen:

- informatieverzameling: opstellen van een compleet overzicht van het huidige geneesmiddelengebruik, aangevuld met een farmacotherapeutische anamnese;

- farmacotherapeutische analyse: systematische beoordeling van indicaties voor medicatie, middelenkeuze, dosering en toedieningswijze, gebruiksvoorschrift, interacties en bijwerkingen, waarbij gebruikgemaakt wordt van de START- en STOP-criteria;

- farmacotherapeutisch behandelplan, op te stellen door huisarts en de apotheker;

- terugkoppeling: bespreking van het farmacotherapeutisch behandelplan door de huisarts met de patiënt en besluitvorming over de uitvoering van het behandelplan.

Voor een medicatiebeoordeling zijn verschillende werkwijzen beschikbaar (zie o. a. www.medicijngebruik.nl), al of niet in FTO-verband. Er zijn goede ervaringen met de inzet van een expertteam, bestaande uit een (huis)arts en een apotheker voor de farmacotherapeutische analyse en het opstellen van het farmacotherapeutisch behandelplan [12].

\section{OVERWEGINGEN BIJ DE MEDICATIEBEOORDELING}

Er zijn op diverse punten kanttekeningen te plaatsen bij de aanbeveling voor een periodieke medicatiebeoordeling in de richtlijn Polyfarmacie bij ouderen. Zoals de richtlijnwerkgroep zelf aangeeft, berust deze aanbeveling grotendeels op het oordeel van experts, en is er slechts beperkt wetenschappelijk bewijs voor de effectiviteit van een medicatiebeoordeling, en voor de vraag welke groep patiënten het meest baat heeft bij een medicatiebeoordeling. In verschillende studies is aangetoond dat medicatiebeoordelingen positieve effecten hebben op het aantal geneesmiddelgerelateerde problemen (bijv. therapietrouw, bijwerkingen), op de kennis van patiënten over hun geneesmiddelen en het gebruik ervan. Maar tot op 
heden zijn nog geen effecten aangetoond op bijvoorbeeld de ervaren kwaliteit van leven, het aantal ziekenhuisopnamen vanwege medicatieproblemen of de kans op sterfte [13].

Er circuleren verschillende adviezen ten aanzien van de doelgroep voor het uitvoeren van een medicatiebeoordeling. Binnen de genoemde criteria uit de richtlijn Polyfarmacie bij ouderen geeft de Inspectie voor de Gezondheidszorg bijvoorbeeld voorrang aan 'alle patiënten van 75 jaar en ouder, die zeven of meer geneesmiddelen gebruiken en een verminderde nierfunctie (eGFR $\left.<50 \mathrm{ml} / \mathrm{min} / 1,73 \mathrm{~m}^{2}\right)$ hebben' [14]. De National Health Service in het Verenigd Koninkrijk suggereert een medicatiebeoordeling te overwegen (1) periodiek in geval van een bestaande chronische aandoening; (2) als een nieuwe chronische aandoening wordt gediagnosticeerd; (3) als een patiënt een ongewenste bijwerking heeft ervaren; (4) als een patiënt of zorgverlener daarom vraagt of aangeeft gestopt te zijn met het gebruik van een voorgeschreven geneesmiddel [15]. Er is dus geen consensus over de doelgroep voor een medicatiebeoordeling, vooral omdat de daarvoor noodzakelijke evidence nog ontbreekt.

Een goede medicatiebeoordeling vereist een gedegen voorbereiding: beoordelaars moeten beschikken over een actueel overzicht van de gebruikte medicatie en de medicatiehistorie, een overzicht van bestaande ziekten en informatie over relevante farmacokinetische parameters als nier- en leverfuncties. De medicatiebeoordeling vindt plaats door twee personen met een respectievelijk medische en farmaceutische expertise. Als de medisch expert niet de eigen (behandelend) huisarts van de patiënt is, wordt het advies voor het farmacotherapeutisch behandelplan naar de huisarts van de patiënt gestuurd.

Een belangrijk element in de medicatiebeoordeling is de betrokkenheid van de patiënt zelf of - zo nodig - een mantelzorger. Intuïtief lijkt dit erg voor de hand te liggen, maar tot nu toe ontbreekt wetenschappelijk bewijs dat het betrekken van patiënten bij de medicatiebeoordeling een meerwaarde heeft [16]. In de fase van de informatieverzameling lijkt de bijdrage van de patiënt onontbeerlijk, om bijvoorbeeld informatie te krijgen over het gebruik van vrij verkrijgbare geneesmiddelen (!), het feitelijk gebruik van voorgeschreven medicatie (medicatielijst correct? gebruik volgens voorschrift?), kennis over geneesmiddelen (welk middel gebruikt de patiënt voor welke aandoening?), over eerdere ervaringen met geneesmiddelen en over ervaren bijwerkingen. Deze informatie kan verkregen worden tijdens een consult, of door het gebruik van een vragenlijst [17]. Maar ook in de laatste fase van de medicatiebeoordeling, als het behandelplan wordt besproken en afspraken gemaakt worden over het medicatieregime, zijn betrokkenheid en instemming van de patiënt essentieel. Betrokkenheid van de patiënt bij de beoordeling van de medicatie creëert het benodigde draagvlak voor het optimaliseren van de medicatie, maar vereist goede voorlichting vooraf:

- Geef uitleg aan de patiënt dat een medicatiebeoordeling plaatsvindt om het geneesmiddelengebruik te optimaliseren (en niet om de patiënt te controleren of om kosten te besparen).

- Benadruk het belang van de eigen inbreng van de patiënt (bijvoorbeeld om de correctheid van de lijst van gebruikte medicatie te checken, en om door de patiënt ervaren bijwerkingen bij de farmacotherapeutische analyse te kunnen betrekken). 
- Geef aan dat het uiteindelijke behandelplan in samenspraak met de patiënt tot stand komt.

\section{TOT SLOT}

Patiënten met multimorbiditeit die ook veel verschillende geneesmiddelen gebruiken vragen om een generalistische benadering door huisartsen. Voor huisartsen vormt deze groep patiënten een uitdaging: hoe kan ik aan hen optimaal huisartsgeneeskundige zorg verlenen, rekening houdend met de bestaande wetenschappelijke kennis, met mijn eigen expertise en praktijkervaring en met de voorkeuren en wensen van de patiënt? De in deze bijdrage besproken systematische werkwijze in de spreekkamer en medicatiebeoordeling kunnen daarbij behulpzaam zijn.

\section{LITERATUUR}

1. https://www.cbs.nl/nl-nl/ciifers (bezocht op 21 juni 2017)

2. Akker M van den, Buntinx F, Knottnerus JA. Comorbidity or multimorbidity: what's in a name? A review of literature. Eur J Gen Pract. 1996;2:65-70.

3. Feinstein AR. The pre-therapeutic classification of co-morbidity in chronic disease.

J Chronic Dis. 1970;23:455-68.

4. Fried LP, Ferruci L, Darer J, Williamson JD, Anderson G. Untangling the concepts of disability, frailty, and comorbidity: Implications for improved targeting and care. J Gerontol A Biol Sci Med Sci. 2004;59:M255-M63.

5. Nederlands Huisartsen Genootschap. Multidisciplinaire richtlijn Polyfarmacie bij ouderen. Utrecht: NHG; 2012.

6. Muth C, Akker M van den, Blom JW, Mallen CD, Rochon J, Schellevis FG, Becker A, et al. The Ariadne principles: how to handle multimorbidity in primary care consultations. BMC Med. 2014;12:223.

7. Burgers J. Persoonsgerichte zorg in richtlijnen: contradictie of paradox? (Oratie). Maastricht: Maastricht University; 2017.

8. Boyd CM, Darer J, Boult C, Fried LP, Boult L, Wu AW. Clinical practice guidelines and quality of care for older patients with multiple comorbid diseases. JAMA. 2005;294:716-24.

9. Muth C, Kirchner H, Akker M van den, Scherer M, Glasziou PP. Current guidelines poorly address multimorbidity: pilot of the interaction matrix method. J Clin Epidemiol. 2014;67:1242-50.

10. Sinnige J, Braspenning JC, Schellevis FG, Hek K, Stirbu I, Westert GP, Korevaar JC. Inter-practice variation in polypharmacy prevalence amongst older patients in primary care. Pharmacoepidemiol Drug Saf. 2016;25:1033-41.

11. Sinnige J, Braspenning J, Korevaar J, Lieshout J van, Westert G, Schellevis F. Medication management strategy for older people with polypharmacy in general practice. Br J Gen Pract. 2016;66:e540-51.

12. Willeboordse F, Schellevis F, Chau SH, Hugtenburg JG, Elders PJM. The effectiveness of optimised clinical medication reviews for geriatric patients: Opti-Med a cluster randomised controlled trial. Fam Pract. 2017; doi:10.1093/fampra/cmx007.

13. Holland R, Desborough J, Goodyer L, et al. Does pharmacist-led medication review help to reduce hospital admissions and deaths in older people? A systematic review and metaanalysis. Br J Clin Pharmacol. 2008;65:303-16.

14. https://www.igz.nl/onderwerpen/curatievegezondheidszorg/medicatieveiligheid/focus op verantwoord voorschrijven/medicatiebeoor deling en polyfarmacie/ (bezocht op 21 juni 2017)

15. Clyne W, Blenkinsopp A, Seal R. A guide to medication review 2008. Liverpool: NHS National Prescribing Centre; 2008. 
16. Willeboordse F, Hugtenburg J, Schellevis FG, Elders P. Patient participation in medication reviews is desirable but not evidence-based: a systematic literature review. $\mathrm{Br} \mathrm{J}$ Clin Pharmacol. 2014;78:1201-16.

17. Willeboordse F, Grundeken LH, Eijkel LP van den, Schellevis FG, Elders PJM, Hugtenburg JG. Information on actual medication use and drug-related problems in older patients: questionnaire or interview? Int J Clin Pharm. 2016;38:380-7.

\section{FigURE AND TABLE}

Figuur 1 Schematische weergave van de Ariadne principles [6]

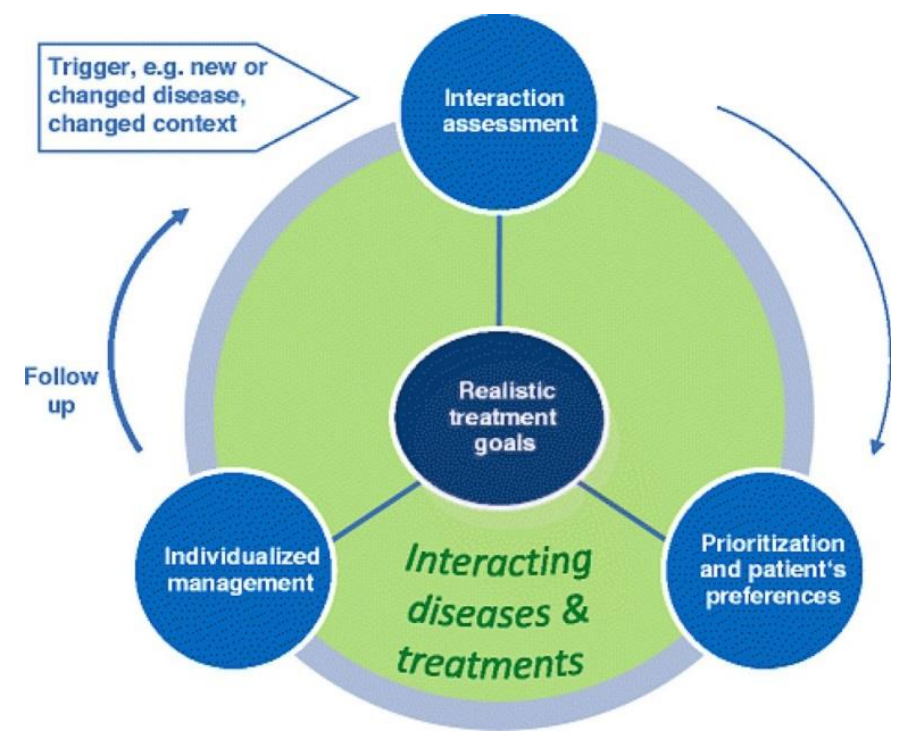

Figuur 2 Aantal polyfarmaciepatiënten per huisartsenpraktijk* $(\mathrm{N}=86)$ onder gebruikers van ten minste één geneesmiddel $(\mathrm{N}$ totaal $=44.917)$ in percentages en $95 \%$ betrouwbaarheidsinterval (gemiddelde $=20,1 \%$; [10]). $(*$ gecorrigeerd voor patiëntkenmerken [leeftijd, geslacht, sociaaleconomische status, aantal en aard van chronische ziekten])

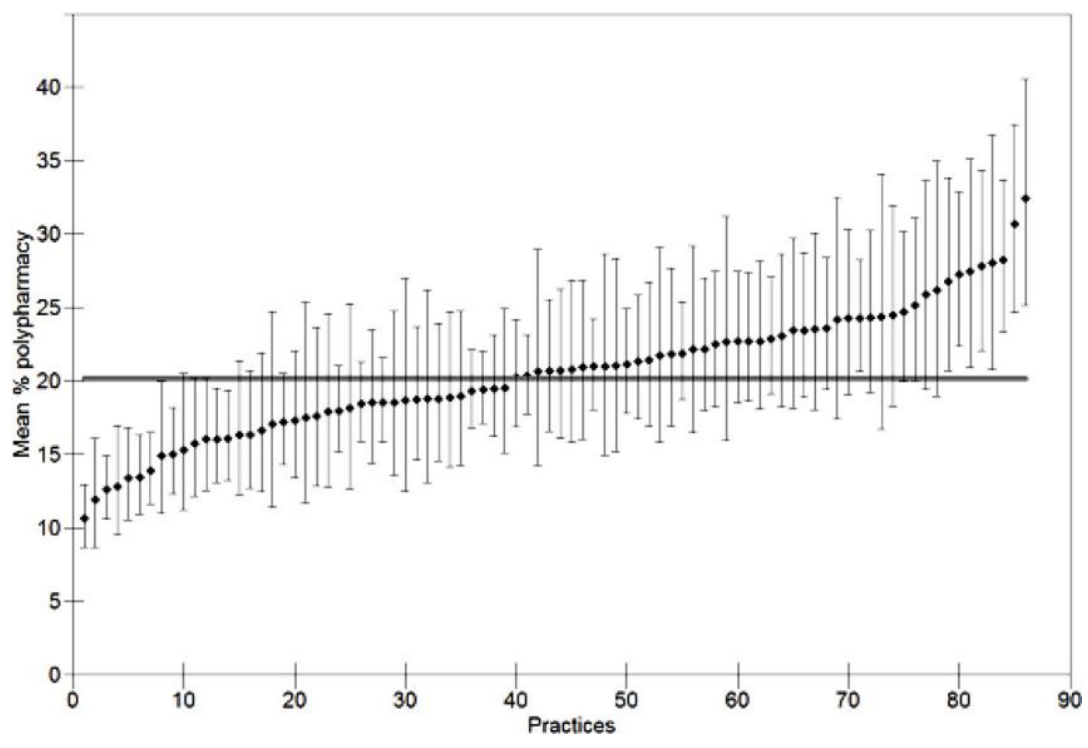

